\title{
VIDA, ARTE E PAISAGEM JANKÉLÉVITCH, LEITOR DE SIMMEL
}

\author{
Joana Quaresma Luís \\ (Doutoranda em Filosofia, FLUL)
}

A arte vem da vida ${ }^{1}$.

Georg Simmel

Envolver-nos-emos, ao longo deste breve estudo, na 'trama' filosófica que se vai tecendo entre a filosofia poiética da música, presente em Vladimir Jankélévitch, e o pensamento genial de Georg Simmel - um autor que, como veremos, marcou profundamente a experiência filosófica jankélévitchiana.

Em primeiro lugar, Jankélévitch terá tomado contacto com a obra de Simmel a partir da influência do seu Pai, Samuel Jankélévitch, psicanalista erudito e de grande subtileza, que traduziu diversos textos de autores alemães para francês, nomeadamente Hegel, Schelling, Freud e Simmel ${ }^{2}$. A sua família, à semelhança de Simmel, era de origem judia o que irá reflectir-se, certamente, no desenvolvimento e na maturação do seu espírito. Compreender a influência judaica seria um tema pertinente e relevante para uma real compreensão das 'fontes' do pensamento filosófico em questão, porém não nos interessará desenvolver aqui essas referências, pois gostaríamos de incidir somente nas possíveis 'relações' ou 'pontes filosóficas' que estabelecem a conexão entre Simmel e Jankélévitch.

1 Georg Simmel, "L'art vient de la vie", "Philosophie du paisage" em La tragédie de la culture et autres essais, trad. Sabine Cornille e Philippe Ivernel, Paris, Rivages, D. L. 1993 , p. 238

2 Simone Zacchini, "Prima di lui Georg Simmel, per probabile diretta influenza paterna, ha avvuto un ruolo certamente non secondario nella formazione della sua sensibilità filosofica.", "La complessità di un uomo semplice", L'altra voce del Logos - Filosofia, musica e silenzio in Vladimir Jankélévitch, Torino, Trauben, 2003, p. 22.

Philosophica, 32, Lisboa, 2008, pp. 31-51 
Inicialmente, podemos encontrar na "filosofia da vida" o ponto de apoio fundamental dos dois autores, pelo que a raiz e o cerne gnosiológico da sua concepção do mundo reside no vitalismo e nas filosofias que exaltam a efectividade da existência (relembrando a Naturphilosophie de Christophe Oetinger, Schelling e Novalis), onde tudo se resume ao termo "vida". De um modo geral, a preocupação com as filosofias vitalistas esteve presente no percurso do jovem Jankélévitch, entre 1922-1930, onde terá dedicado alguns artigos a este tema: o célebre prefácio à tradução francesa de La tragédie de la culture et autres essais, intitulado "Georg Simmel, philosophie de la vie" e também poderíamos citar dois textos igualmente importantes "Deux philosophes de la vie: Bergson, Guyau" e "Les thèmes mystiques dans la pensée russe contemporaine", que actualmente foram editados na colectânea Premières et dernières pages ${ }^{3}$. Existe igualmente um outro texto, L'alternative ${ }^{4}$, publicado em 1938, que é considerado, possivelmente, como sendo uma inspiração directa de Simmel.

O nosso estudo terá como finalidade elaborar um paralelismo entre as filosofias jankélévitchiana e simmeliana, através da criação de um cruzamento ou de uma simbiose entre os autores, mantendo, essencialmente, como base os textos anteriormente citados. Trata-se de uma 'releitura' de Simmel a partir das palavras do próprio Jankélévitch, visto que não iremos analisar Simmel a partir dos seus próprios textos, citaremos somente pequenas passagens, sem a pretensão de realizar um trabalho exaustivo de análise hermenêutica do autor. Semelhante tarefa não caberia neste pequeno trabalho, pelo que iremos incidir exclusivamente na "interpretação" realizada por Jankélévitch, de maneira a expor, de uma forma sintética, qual a 'recepção' da obra simmeliana, vendo o modo como foi assimilada e apreendida.

\section{1. "Filosofia da Vida”. Emergência de um novo paradigma gnosioló- gico}

Em torno do termo "vida" vai gerar-se progressivamente um novo paradigma gnosiológico que, no final do século XIX, será responsável pela criação de uma nova dimensão do conhecimento que irá contrastar drasticamente com o sistema idealista alemão. Vladimir Jankélévitch entende que este súbito interesse pela "vida" terá a mesma relevância que outrora tiveram a ideia de "substância" e de "natureza" na história da filosofia, pois representa a procura pelo ser das coisas, a busca incessante

3 V. Jankélévitch, Premières et dernières pages, Paris, Seuil, 1994.

4 Idem, L'alternative, Paris, Alcan, 1938. 
pelo fundo ontológico último que consiga justificar e sustentar toda a concepção do homem e do mundo 5 .

Ao analisar a expressão "vida" não devemos tomá-la somente como uma referência à vida exterior, no sentido orgânico ou fisiológico de operações vitais, mas pretendemos considerar uma acepção de vida que abarque toda a profundidade da existência. 'Viver' surge, assim, como uma maneira de experienciar e vivenciar o modo de estarmos e sermos vivos num mundo igualmente vivo, pelo que a vida remete sempre para o sujeito que tem uma experiência e uma vivência da mesma. Poderemos salientar que existe, aqui, uma aproximação à noção fenomenológica da intencionalidade, característica da consciência que se abre e se debruça sobre o mundo, afirmando o sujeito, enquanto centro do conhecimento, que produz em si a vivência (Erlebnis). Ora, esta vivência implicará um papel activo do ser humano que não passa simplesmente pela vida de um modo passivo, mas vive-a de uma forma activa e interagindo constantemente com o mundo.

Neste contexto, o carácter activo do homem e da vida vão abrir-nos para uma filosofia vitalista, apresentando um ritmo e um movimento constante, o que leva Jankélévitch a comparar, diversas vezes, o 'fluxo da vida' com o ritmo dos andamentos musicais. A música, tal como a vida, é constituída por som e silêncio que, alternadamente, dão lugar ao ritmo e a todo dinamismo musical. Do mesmo modo, a vida aparece-nos como um conjunto de momentos, de instantes sucessivos, que começam e logo terminam, dando-nos a impressão de uma 'continuidade descontinua' e de um 'fluxo de vivências', para utilizar a expressão husserliana, que é activo e dinâmico. Contemplamos, neste ponto, a presença de um novo paradigma filosófico que Simmel nomeia de "atitude heraclitiana", que surge em oposição à "atitude eleática". Na sua obra Einleitung in die Moralwissenschaf ${ }^{6}$, ambas as vertentes são apresentadas como dois pólos do conhecimento ou duas atitudes distintas perante a realidade, que levam o homem a aceder ao mundo de uma determinada maneira". A "atitude eleática", tal como o termo indica, remete-nos para o período clássico da

5 "Georg Simmel a noté quelquer part que si l'on condense dans uns formule simple, pour chaque période de l'histoire, les aspirations directrices et les principes généraux dans lesquels s'est exprimée la réflexion humaine, c'est bien l'idée de substance qui résumera les tendences les plus profondes du génie hellénique; c'est l'idée de Dieu qui sera le centre de convergence de la spéculation médiévale, et c'est par l'idée de nature qu'il faudra traduire l'idéal de la Renaissance. L'idée de nature, dominante aux XVe - XVIe siècles, est remplacée au XIXe par l'idée de vie qui traduit peut-être encore les aspirations les plus secrètes de notre siècle." V. Jankélévitch, "1. Deux philosophes de la vie: Bergson, Guyau", Premières et dernières pages, p. 16.

${ }^{6}$ Einleitung in die Moralwissenschaft. Eine Kritik der etischen Grundbegriffe (1892-1893).

7 V. Jankélévitch, Préface, La tragédie de la culture et autres essais, p. 13. 
escola de Eleia, cujo principal representante é Parménides e a sua filosofia monista. Tal filosofia assenta na imutabilidade e na unidade do ser, e Simmel afirma que podemos encontrá-la reflectida na arte grega "petrificada para a eternidade no mármore branco do Parthénon". A outra vertente aparece-nos como a "atitude heraclitiana" que, embora esteja presente no pensamento grego, parece ser uma corrente secundária, porque faz alusão às doutrinas orientais e místicas em voga naquela época. $\mathrm{O}$ seu centro, como não poderia deixar de ser, encontra-se expresso na filosofia 'obscura' de Heraclito, que tornar-se-á, todavia, um dos temas centrais do pensamento moderno, a partir de Goethe, passando por Schopenhauer e Nietzsche. A ideia do "fluxo vital" ou "fluxo de vivências" contém em si o espírito da filosofia heraclitiana, as águas do rio que passam... o efémero de cada instante que vai passando e que nunca poderá ser recuperado. Ora, esta efemeridade ou inefabilidade da existência tornam os momentos da vida únicos e irreversíveis, na medida em que a vida está numa mutação permanente. A "atitude heraclitiana" defende, neste sentido, um pensamento aberto à noção de experiência e de movimento que se contrapõe ao pensamento estático das filosofias monistas. Jankélévitch, influenciado totalmente por Simmel, reconhece que somente uma "filosofia da vida" poderá captar esta riqueza infinita do instante.

Simmel considera que poderemos encontrar em Goethe o melhor representante destas duas grandes concepções do mundo, na medida em que reúne em si o pólo sintético e o pólo monista simultaneamente. A verdadeira filosofia deve conciliar o intelectualismo, por exemplo, kantiano, que está muito apegado a um sistema de conceitos e uni-lo à força da ordem vital da existência, formando-se, assim, uma junção entre o pensamento intelectual e a imprevisibilidade dos dados da vida espontânea ${ }^{9}$. Este novo 'sistema' terá como percursora toda a escola romântica alemã, sobretudo, o pensamento de Schelling e de Novalis que criam uma aproximação entre o ideal e o real, entre filosofia da natureza e a filosofia da arte, abrindo as portas para a noção de vida e de vitalismo. A simbiose entre o plano intelectual dos conceitos e o plano da experiência da ordem vital vai estar presente na dialéctica do Quid e do Quod schellingiana que revela, por um lado, a procura da essência (Quid sit) e, por outro lado, a experiência de constatação do existente (Quod sit): o quid dá prioridade à essência, manifestando-se no Idealismo e Racionalismo, e o quod confronta-se com a experiência, com a efectividade e com a presença da coisa manifesta. A "filosofia da vida" de Simmel vai situar-se, deste modo, na linha do 'positivismo' de Schelling, realizando o que Jankélévitch designa de "filosofia da presença" que é uma filosofia do aparecer, da

\footnotetext{
8 Ibidem, “[...] pétrifiée pour l'éternité dans le marbre blanc du Parthénon.”, p. 13.

9 Ibidem, p. 14.
} 
manifestação e do fenómeno (phainomenon) que se desvia claramente da noção do ser estático e imutável de Parménides, bem como do ser enquanto 'Motor-Imóvel' de Aristóteles.

A Naturphilosophie ${ }^{10}$ dos românticos defendia a existência de um processus activo e inteligente da natureza, uma geração do ser, uma força ascensional que impulsiona o crescimento daquilo que se encontra em gérmen, em potência, até à sua realização efectiva. Este processo designa-se de ordo generativus, a dinâmica segundo a qual a natureza, na sua fecundidade imanente, movimenta-se de acordo com um devir ascensional, desencadeando, assim, todos os seres. Segundo Schelling, tanto o produto natural como o produto estético derivam deste processo criador que se produz inconscientemente, pois são retirados da massa informe do Ungrund, convertendo toda a natureza e a arte numa 'operação da vida'. Encontramos aqui, diz Jankélévitch, uma reunião da arte e da natureza que exprimem o real de forma objectiva, fugindo do carácter subjectivo do Idealismo iluminista, na medida em que a filosofia de Schelling cria uma espécie de "empirismo filosófico" que reúne o elemento formal, presente na 'intuição intelectual', com o elemento vital, presente na natureza. Dá-se, deste modo, uma união entre o eu subjectivo e a natureza objectiva mediante uma ligação intuitiva que, de certo modo, antecipa já o intuicionismo do pensamento de Bergson. O sistema gnosiológico que era considerado, em Kant, como algo estático, passar a ser, na filosofia de Simmel e Bergson, uma combinação dinâmica das revelações da intuição.

A crítica que Jankélévitch vai dirigir, ao longo de toda a sua obra, em relação ao kantismo é sustentada pelo relativismo filosófico levantado por Simmel. Apesar de Kant ser um autor genial, o seu sistema não colhe a diversidade e a imprevisibilidade da vida, porque une um esquema de conceitos vazios às intuições da experiência, o que significa que a estrutura formal é aplicada aos dados da experiência e é precisamente esse esquema formal que dá sentido e orienta as impressões desorganizadas sob a forma de intuições. Daí, a célebre expressão kantiana referir que os conceitos sem intuições são vazios e as intuições sem conceitos são cegas, através da qual Kant demonstra a sua intenção de querer conciliar, de certo modo, o puro subjectivismo com o empirismo sensualista. Todavia, a prioridade é aqui dada ao formalismo, à subjectividade do sujeito do conhecimento, ou seja, ao subjectivismo transcendental e aos seus elementos a priori: espaço e tempo ${ }^{11}$. $\mathrm{O}$ apelo à vida na obra de Simmel não poderia aceitar este prima-

10 "Les romantiques allemands de la Naturphilosophie, Schelling en particulier, avaient, nous l'avons vu, combiné et fondu dans leur systéme en une synthèse originale deux points de vue distincts: celui de l'évolutionnisme et celui du vitalisme." Idem, Premières et dernières pages, p. 17.

11 "Le kantisme essaie de faire le synthèse de ces deus conceptions, puisque, d'une part, toute connaissance est systématique, dans le mésure où elle résulte d'un sys- 
do da forma estática, que Kant nos impõe como se fosse uma espécie de absoluto, visto que qualquer forma não deve ser rígida e deverá ser susceptível de modificação, adaptando-se plasticamente às movimentações do fluxo vital. Não se trata apenas de um sistema de conceitos que são aplicados peremptoriamente aos dados sensíveis, será importante compreender que os dados sensíveis, a vida, também vai introduzir alterações no sistema conceptual. O sistema não se desenvolve uniteralmente, ou seja, do sujeito que 'molda' os objectos, mas desenvolve-se numa interacção recíproca entre sujeito e objecto. Segundo Jankélévitch, acentuar o pólo racional só irá contribuir para desequilibrar a harmonia e a sintonia que deve existir entre o pensamento e as coisas ${ }^{12}$. No fundo, as filosofias vitalistas de Schelling e Bergson ${ }^{13}$ vão dar uma maior ênfase à experiência imediata que ainda não foi mediada pelos conceitos, uma espécie de primeira impressão ou de primeiro olhar sobre realidade. Jankélévitch procurá a vivência pura, o instante primordial onde o homem olha pela primeira vez para o mundo e sente-se fascinado perante o desconhecido, o momento original onde os discursos linguísticos ainda não têm lugar, por isso em consonância com Simmel refere: "O ser em geral não pode ser demonstrado, mas apenas vivido e sentido; não saberíamos, por consequência, deduzi-lo de conceitos abstractos. "14 Contemplamos, deste modo, um desejo de retorno à inocência do homem, e usando a expressão husserliana, poderíamos afirmar que existe, indubitavelmente, um retorno ao "mundo-da-vida" (Lebenswelt).

Resta saber de que forma se realiza este 'retorno' ao mundo-da-vida... Segundo Simmel, a filosofia subjectiva de Kant esqueceu-se do homem enquanto ser histórico e enraizado no mundo. Neste sentido, a filosofia simmeliana, embora pertença à tradição criticista, irá reconhecer as lacunas do sistema kantiano e tentará 'colmatá-las', concebendo o homem não

tème d'a priori - les formes de notre connaissance -, mais que, d'autre part, les donnés sensibles auxquelles s'appliquent ces formes sont susceptibles d'évolution et de variations infinies. Systématique du fait de l'extension infinie de son champ. Solution génial, dit Simmel, mais qui ne saurait pourtant nous satisfaire aujourd'hui, car le formalisme kantien est trop rigide; et nous ne pouvons plus céder à la tentation du sustème, ce système fût-il seulement celui des formes de la connaissance. Pour être fidèle à ce qu'il y a de plus profond dans l'inspiration kantienne, il fait assouplir le formalisme, il faut rendre à l'esprit son caractère de réalité vivante, fluide, changeante, en un mot, historique." François Léger, La pensée de Georg Simmel, Paris, Kime, 1989, p. 120.

12 V. Jankélévitch, Préface, p. 18.

13 Ibidem, "Comme Simmel, Bergson reproche à Kant d'ériger la forme intellectuelle de notre connaissance en une espèce d'absolut, de renoncer à faire la genèse de l'entendement et de ses catégories: 'les cadres de l'entendement et l'entendement lui-même devraient être acceptés tels quels, tout fais'.", Préface, p. 16.

14 Ibidem: "L’être en général ne peut être démonstré, mais seulement vécu et senti; on ne saurait, par conséquent, le déduire de concepts abstraits.”, p. 19 
somente como um "Dasein" estático, mas "enriquecendo a vida do eu sob todas as formas: intelectual, moral, estética ou religiosa" 15 . Profundamente marcado pelo vitalismo e intuicionismo romântico, Simmel vai encontrar personificada na figura de Goethe toda a expressão do génio e dos ideais românticos, buscando incessantemente pela noção de infinito na vida moral, intelectual, estética e religiosa, que se designou de Sehnsucht - expressão obscura e complexa que surgiu, sobretudo, no seio da arte, fundamentada por Hölderlin, Novalis, Schumann e Schopenhauer.

Para Frédéric Schlegel e Novalis, por exemplo, bem como M. Th. Steppoune o demonstrou com precisão, o mérito essencial do criticismo teria consistido em aniquilar a polaridade do sujeito e do objecto, absorvendo no sujeito este além transcendente e resistente, que forma em aparência o não-eu; o sujeito de Kant, como síntese activa de uma multiplicidade empírica, torna-se assim em Fichte o eu criador e concreto, rico da plenitude infinita do não-eu que se dissolve nele; o eu transcendental, que, em Kant, determinava apenas a ordem e o sentido dos objectos conhecidos, determina, de acordo com Fichte, a sua existência própria. Mas os românticos logo reconheceram que o kantismo primitivo estava longe implicar por si mesmo tal intensidade de lirismo; pareceu que Kant não teria sabido deduzir das suas premissas lógico-transcendentais toda a riqueza espiritual dos conteúdos da vida; pareceu que ao colocar o primado do 'a priori', Kant entronizava simplesmente uma forma árida, pobre e frágil: esta forma, seria necessário fecundá-la com a plenitude concreta das experiências afectivas, estéticas e religiosas, tal como se desabrocham, por exemplo, na personalidade de um Goethe. Sabe-se, quanto a Georg Simmel e seus discípulos, que lhes agrada actualmente oporem Kant e Goethe: [...] o grito de guerra da escola relativista "Zurück zu Goethe!" - Regresso à Goethe!16

15 Ibidem "[...] à enrichir la vie du moi sous toutes ses formes: intellectuelle, morale, esthétique ou religieuse.", p. 13.

16 Idem, "Pour Frédéric Schlegel et Novalis, par exemple, ainsi que M. Th. Steppoune l'a montré avec justesse, le mérite essentiel du criticisme aurait consisté à anéantir la polarité du sujet et de l'objet en absorbant dans le sujet cet Au-delà transcendant et résistant qui forme en apparence le non-moi; le sujet Kant, comme synthèse active d'une multiplicité empirique, devient ainsi chez Fichte le moi créateur et concret, riche de la plénitude infinie du non-moi qui se dissout en lui; le moi transcendantal, qui chez Kant ne déterminait que l'ordre et le sens des objets connus, détermine selon Fichte leur existence elle-même. Mais les romantiques durent bientôt reconnaître que le kantisme primitif était loin d'impliquer par lui-même une telle intensité de lyrisme; il apparut que Kant n'avait pas su déduire de ses prémisses logico-transcendentales toute la richesse spirituelle des contenus de la vie; il apparut qu'en posant le primat de l'a priori, Kant intronisait tout simplement une forme sèche, pauvre et cassante: cette forme, il fallait la féconder avec la 
Será na sua obra Lebensanschauung ${ }^{17}$ que Simmel expõe a sua posição relativamente à "filosofia da vida", na sua vertente moral, social, cognitiva, estética e religiosa. Jankélévitch considera que esta obra é particularmente fascinante não só pelo estilo de escrita de Simmel, mas sobretudo pela formidável profundidade do seu pensamento, que nos introduz numa nova e misteriosa concepção do homem enquanto "ser intermediário" (Mittelstellung), um ser que se encontra numa constante errância, evoluindo em diversos sentidos, sempre com a finalidade de encontrar-se a si próprio ${ }^{18}$. Mediante este esforço de procura, o homem vai reconhecendo as suas limitações e tenta vencê-las, sonhando alcançar o absoluto. Este vai ser o sentido da expressão Selbsttranszendenz, que exprime claramente o desejo de transcender-se a si próprio ${ }^{19}$, ultrapassando, de certo modo, os limites que o condicionam ${ }^{20}$. Tamanha transgressão e superação dos limites aparece-nos como a atitude filosófica por excelência, que também vai estar presente no domínio artístico e religioso.

\section{Estética Vitalista. Lebensanschauung - A intuição da vida e as suas repercussões do domínio artístico}

À semelhança de Georg Simmel, a filosofia jankélévitchiana vai distanciar-se do Idealismo subjectivo, criticando o 'império do logos' das filosofias racionalistas, na medida em que procura uma abordagem intuitiva da realidade, que permita ao homem sentir e vivenciar as coisas não de uma forma estritamente conceptual ou formal, mas de um modo inteiramente novo - seguindo as suas impressões e vivências que lhe permitem aceder à vida em si mesma.

Enquanto que Simmel refuta o Idealismo kantiano, Jankélévitch critica igualmente o modelo cartesiano de filosofia, que assenta na construção do 'edifício do saber', no conhecimento puramente racional baseado

plénitude concrète des expériences affectives, esthétiques et religieuses, telle qu'elles s'épanouissent, par exemple, dans la personnalité d'un Goethe. On sait combien Georg Simmel et ses disciples se plaisent aujourd'hui à opposer Kant et Goethe: [...] le cri de guerre de l'ecole relativiste «Zurück zu Goethe!» - Retour à Goethe!", "7. Les thèmes mystiques dans la pensée russe contemporaine", Premières et dernières pages, pp. 110-111.

17 Lebensanschauung, Vier Metaphysische Kapitel (1918).

18 V. Jankélévitch, Préface, p. 27.

19 Ibidem, “'Selbsttranszendenz': c'est l'idée suivant laquelle le présent n'est en réalité que la limite idéale et intemporelle du passé et du futur, alors que le passé soit par la mémoire, soit par la généralisation, c'est-à-dire par la création de concepts objectifs, soit encore par l'imagination spéculative, se survit à lui-même dans le présent et se prolongue dans l'avenir", Préface, p. 33.

20 Ibidem, Préface, p. 31. 
em evidências e raciocínios. Será necessário compreender que o verdadeiro conhecimento é da ordem do 'vivido' e não apenas do 'pensado' e que só poderemos efectivamente obter conhecimento através de um sistema 'vital' que supere a constante dicotomia entre sujeito-objecto ${ }^{21}$.

Será importante salientar que existem, de facto, algumas semelhanças entre a "filosofia da vida" de Simmel e a fenomenologia de Husserl, visto que ambos pretendem um retorno ao 'mundo-da-vida'. Porém, mais um vez, nos questionamos acerca deste 'retorno' e de que modo ambos os filósofos o vão realizar. Husserl, pioneiro da Fenomenologia, dirá que é necessário construir a filosofia enquanto "ciência de rigor", encontrando no cogito racional o fundamento de toda a filosofia. Aqui o sujeito é identificado unicamente como 'consciência' pura que se caracteriza pelo seu fluxo de vivências. Ora, na filosofia defendida por Simmel e Jankélévitch, o sujeito não se define apenas em termos da sua racionalidade ou consciência, pois vai ser definido como um todo: o homem é corpo e alma, o homem é "vida". Por este motivo, a sua filosofia, acrescenta Jankélévitch, não vai centrar-se exclusivamente numa análise de carácter racionalista, vai virar-se para a intuição, para o amor e para as 'vivências da vida' do sujeito. Todavia, seria essencial frisar que a 'vivência jankélévitchiana' distingue-se totalmente da 'vivência husserliana', porque não se apresenta como uma vivência depurada fenomenologicamente. Encontrar a vivência profunda não pressupõe uma espécie de 'dissecamento' racional dos dados da consciência, afastando todas as coisas mundanas de maneira a encontrar a 'invariável' e o cogitatum puro. A vivência husserliana torna-se, na perspectiva de Jankélévitch, um conteúdo árido, encerrado num cogito solipsista, privado do sentido passional, físico e real, que lhe retira, por assim dizer, toda a vida. Por conseguinte, Jankélévitch vai aliar-se ao pensamento de Simmel com o único intento de defender uma vivência ligada à "vida", à recordação nostálgica de cada instante, uma percepção da passagem do tempo filtrada pela intuição pura do amor. Encontrar a vivência pura pressupõe tão somente um estado de atenção amorosa a cada momento da vida, o sentido do kairos nos gregos, onde se experimenta o sentimento de nostalgia provocado pela evanescência do instante. Estamos perante uma alma romântica, musical e sonhadora que pretende formar uma filosofia da música e do amor, encontrando na questão do amor uma forma de superar o racionalismo dogmático kantiano do sujeito encerrado em si mesmo.

Numa tentativa de derrubar definitivamente o Idealismo, Jankélévitch aproxima-se da filosofia de Pascal, que conseguiu rasgar o raciona-

21 Ibidem, "En somme, la Vie est un absolut supérieur à la dualité conceptuelle de l'object et du sujet.", Préface, p. 41 
lismo através do irracionalismo abrupto do amor ${ }^{22}$. $\mathrm{O}$ amor desempenhará na sua obra a mesma função que a Selbsttranszendenz ocupa na filosofia de Simmel, ou seja, manifesta-se como uma forma de superação dos limites, uma saída de si próprio. Assumindo-se, assim, como uma natureza transbordante, um excesso que provém do interior do homem, mas ao mesmo tempo, ultrapassa-o e transcende-o. Jankélévitch considera que o amor surge como a máxima experiência do inefável, e tal 'experiência' não se exprime em palavras, pois entre a 'experiência' e o 'dizer' existe um hiato que é intransponível. Quando o homem não possui mais palavras que consigam exprimir aquilo que está a vivenciar, depara-se com os limites de si mesmo, e, nesse instante, onde as palavras não fazem mais sentido, surge a dimensão do silêncio. O silêncio vai representar não só a incapacidade e a indigência do homem perante a vida que o ultrapassa, mas também coloca em confronto a finitude do homem perante da infinidade da vida. Neste momento último, onde as palavras deixam de fazer sentido e os discursos se silenciam, emerge misteriosamente o reino das artes, com especial relevo, a música.

No domínio da estética, Jankélévitch considera que o pensamento de Simmel poderá ter uma grande influência na sua estética musical, porque reconhece que este autor segue a linha de Schopenhauer e da filosofia romântica alemã, demonstrando que "a obra de arte é uma combinação dinâmica de uma forma e de uma matéria, é intermediária entre a subjectividade pura e a pura objectividade"23. O autor propõe uma "síntese vital' entre a forma do pensamento e o conteúdo empírico, convertendo a arte numa 'estética vitalista', que possa manifestar a grandeza sublime da vida. Vladimir Jankélévitch afirma que poderíamos resumir toda a filosofia da arte simmeliana mediante dois termos fundamentais: Selbstgenügsamkeit e Fürsichsein, que indicam respectivamente a 'auto-suficiência' da obra de arte e o facto da obra ser uma 'unidade para si mesma', que se encontra fechada em si, formando "uma síntese e uma antítese de tudo em conjunto"24. Isso significa que a obra não está totalmente aberta para o homem, pois vive do seu isolamento e concentra-se na sua unidade que lhe concede coesão e sentido. Poderíamos salientar

22 Idem, "Le logos a ses limites, et il faut bien en tenir en compte. Chez nos classiques, chez Corneille, Racine, Bossuet, Pascal, le cardinal Retz, Montesquieu, le je-ne-sais-quoi exprime le premier désarroi du rationalisme scandalisé par les causes dérisoires de l'amour, par la disproportion des causes et des effets, si injurieuse pour la raison, enfin par ces ébranlements infinitésimaux et ces motivations microscopiques qui sont les seules raisons du coeur.", La manière et l'occasion, Le je-ne-sais-quoi et le presque-rien, Paris, Seuil, 1980, p. 46.

${ }^{23}$ Idem, “[...] l'oeuvre d'art, combinaison dynamique d'une forme et d'une matière, est intermédiaire entre la subjectivité pure et la pure objectivité.”, Préface, p. 42.

24 Ibidem, "[...] une synthèse et une antithèse tout ensemble.”, Préface, p. 43. 
que se verifica um movimento 'centrípeto' da obra de arte que gira sobre si, enclausurando-se na sua individualidade espiritual.

[...] uma obra bela que, sem se dissolver num recuo exagerado nas brumas do númeno inacessível, revela, contudo, uma forte centralização, provoca na nossa consciência mil 'tensões' secretas e interioriza-se tanto mais que forma por si mesma um todo mais objectivo. ${ }^{25}$

Relembrando Schopenhauer, Simmel considera que o único papel do homem, enquanto espectador, consiste somente em contemplar a obra de arte, que contribui para enriquecê-lo na sua interioridade. Por sua vez, a alegria que sente na contemplação irá reflectir-se na obra, como se existisse um movimento recíproco, onde o homem e a obra se espelhassem ambos um no outro, completando-se mutuamente.

O grande interesse pela estética romântica vai revelar-se essencialmente na exaltação do grande compositor Robert Schumann que, segundo Jankélévitch, foi a verdadeira "realização do ideal simmeliano"26, embora Simmel não tivesse consciência desse facto devido aos seus escassos conhecimentos no domínio da música alemã. A música romântica surge como uma expressão poderosa da força da vida e não pode ser mais concebida, do ponto de vista estético, enquanto um mero jogo de sensações ou como "L'art pour l'art"27. Assim se explica o uso de termo Sehnsucht para designar a aspiração religiosa e nostálgica do Absoluto, a procura do infinito e do ilimitado que escapa sempre ao humano. Somente uma "estética vitalista", que se baseia na vida como uma transcendência contínua da estrutura formal estática e determinada, pode expressar a autenticidade e a liberdade que implica o impulso artístico ${ }^{28}$.

Georg Simmel criticará, no domínio da arte, precisamente o mesmo carácter formalista que existe na filosofia do conhecimento kantiana. A tendência ao formalismo não permite a verdadeira 'erupção' da arte enquanto excesso ou uma espécie de extravasamento da vida. Por conse-

25 Ibidem, “[...] une ouevre belle qui, sans s'effacer par une recul exagéré dans les brumes de l'inacessible noumène, révèle cependant une forte centralisation, provoque dans notre conscience mille 'tensions' secrètes et s'intériorise d'autant plus qu'elle forme par elle-même un tout plus objectif.", pp. 44-45.

26 Ibidem, “[...] la vivante réalisation de l'idéal simmélien.”, Préface, p. 49.

27 Werner Jung, "Radikaler noch als der Deutsche Idealismus - uns sichtlich beieinflußt von der zeitgenössichen L'art pour l'art Bewegung - vertritt Simmel den Autonomie-Gedanken der Kunst. [...] Das Kunst ist des absolut Andere des Lebens, weil und insofern es Form ist.", Georg Simmel - zur Einführung, Hamburg, Junius Verl, 1990, p. 135.

28 Simone Zacchini, “2. L'estetica vitalista in Simmel e Schumann”, L'altra voce del Logos - Filosofia, musica e silenzio in Vladimir Jankélévitch, Torino, Trauben, 2003, pp. 36-37. 
guinte, Jankélévitch refere que "A realidade viva atravessa e ultrapassa todos estes conceitos estreitos e exclusivos que designamos de moralidade, inteligência, religiosidade, arte"29, pelo que devemos formar uma concepção estética que seja realizada segundo a máxima: $A$ Vida pela Arte e a Arte pela Vida.

A teoria do génio vai representar, neste contexto, a matriz que justifica o impulso da criação artística e que fundamenta esta estética vitalista. Tal matriz de origem romântica remete-nos para Nietzsche, aludindo à relação entre o apolíneo e o dionisíaco - o pólo racional e o pólo vital que possuem uma inter-relação profunda e trágica. Do mesmo modo, a noção de génio será, em Simmel, uma ligação entre o aspecto formal e o dinamismo vital e original, que poderemos encontrar bem patente nas peças musicais de Schumann. De acordo com a visão jankélévitchiana, Schumann é uma concretização da ideia de Selbsttranszenden, na medida em que as suas obras quebram com a tradição clássica e abrem-se para a fantasia romântica. Os compositores românticos deram uma maior ênfase à fantasia, porque designa algo que está fora dos cânones clássicos e é tomada pelos românticos como uma espécie de oposição à estrutura estrita da sonata, por exemplo de Beethoven ${ }^{30}$. Por este motivo, Jankélévitch refere que a fantasia sugere uma maior criatividade e um espírito de improvisação poético procurando libertar-se dos 'grilhões' rígidos da estrutura clássica ${ }^{31}$.

Não há senão um absoluto na música de Schumann: É a vida sintética e profunda, subjacente ao mesmo tempo aos conteúdos que electriza e às formas flexíveis onde se encarna provisoriamente; vida ardente na qual sujeito e objecto, ligados entre si por mil correspondências secretas, mil afinidades misteriosas se contraiem, por assim dizer, num acto único e simples cuja a inexprimível tonalidade concede ao lirismo schumanniano o seu encanto excepcional e o seu intuitivo frescor ${ }^{32}$.

${ }^{29}$ V. Jankélévitch, "La realité vivante traverse et déborde tout ces concepts étroits et exclusifs qu'on appelle moralité, intelligence, religiosité, art.", Préface, p. 55.

30 Charles Rosen, "Sonata form after Beethoven", Sonata forms, New York - London, Norton \& Company, 1988, pp. 365-408.

31 V. Jankélévitch., "Partout où le mot 'fantaisie' figur en sous-titre, il annonce un relâchement da la riguer, une licence, une approximation poétique.", Nocturne, La musique et les heures, F. Schwab (ed), Paris, Seuil, 1988, p. 278.

32 Idem, "Il n'y a qu'un absolut dans la musique de Schumann: c'est la vie synthétique et profonde, sous jacent à la fois aux contenus qu'elle électrise et aux formes flexibles où elle s'incarne provisoirement; vie ardente dans laquelle sujet et objet, liés entre eux par mille correspondences secrètes, mille affinités mystérieuses se contractent, pour ainsi dire, en un acte unique et simple dont l'inexprimable tonali- 
A filosofia da arte em Simmel apresenta-se, na perspectiva de Jankélévitch, como uma constante ligação entre 'idealismo' e 'realismo' estético. Defender tanto o Idealismo puro ou o Realismo puro é uma atitude quimérica, visto que as posições absolutas são sempre incoerentes e empobrecedoras. A sua finalidade será demonstrar a ligação essencial de ambas as concepções, pois a criação estética será sempre, por um lado, 'realista', visando as coisas reais de um modo imediato, e, por outro lado, será 'idealista', no sentido em que este carácter imediato, esta imediatez, só é conseguido mediante uma experiência intuitiva e especulativa que se devem a um esforço de interiorização do sujeito.

\section{A noção de Stimmung na Filosofia da Paisagem e na Filosofia da Música}

De acordo com a interpretação jankélévitchiana, toda a filosofia da arte de Georg Simmel aparece-nos como uma estética vitalista que, de certo modo, se baseia no 'mal-entendido', que se gerou em torno do debate entre Idealismo e Realismo. O vitalismo pretende reunir tanto o elemento ideal como o elemento real, colocando-os em equilíbrio, na medida em que os valores estéticos apresentam-se simultaneamente como subjectivos e objectivos. Existe efectivamente uma manifestação da alma do artista na sua obra, porém existe uma independência da obra relativamente à individualidade do artista, no sentido em que a obra está em ligação imediata e objectiva com o real, e vale por si mesma, possuindo uma unidade que a rodeia e lhe concede toda a coerência (tal como poderemos ver expresso nos dois termos Selbstgenügsamkeit e Fürsichsein). No fundo, não existe verdadeiramente um 'debate' ou uma 'oposição' entre o Idealismo ou Realismo, na medida em que ambos devem completar-se mutuamente, exibindo uma inter-relação enriquecedora do ponto de vista estético e gnosiológico. Vai ser, sobretudo, através da arte que se consegue revelar melhor esta relação entre o ideal e o real, entre o subjectivo e objectivo, entre o sujeito e o objecto.

Encontraríamos igualmente na obra Georg Simmel traços desta estética vitalista. Para Simmel tal como para Bergson e Guyau, a partir de um mal-entendido é que nasceu o debate entre idealismo e realismo: os valores estéticos são ao mesmo tempo objectivos, naquilo o sujeito thes projectou, muito distante da sua consciência individual, e subjectivos, quanto mais a arte manifesta uma grande independência em relação à individualidade, mais ele tende a tradu-

té donne au lyrisme schumannien son charme exquis et son intuitive fraicheur.", Préface, p. 50 
zi-la de uma maneira profunda e imediata. A arte, como que por um golpe de varinha mágica, derruba as barreiras que se interpõem entre o sujeito e o objecto: exprimindo a vida imanente às coisas, transporta-nos rapidamente ao seio da realidade absoluta, ao mesmo tempo que nos faz tocar o subsolo obscuro do nosso eu individual. Esta estética, com o seu carácter profundamente imanentista e vitalista, assemelha-se ainda àquela de Bergson ${ }^{33}$.

Jankélévitch considera que, tanto Simmel como Bergson, vão dar relevo à noção de uma simpatia entre o sujeito e o objecto que lhes permite coincidirem um com o outro, transportando-nos para o seio da realidade absoluta. Através da intuição, uma determinada visão do objecto é transmitida ao sujeito, visto que a capacidade intuitiva realiza uma simplificação, mediante a qual o sujeito apreende a totalidade de uma forma imediata, reunindo aquilo que está disperso num todo ${ }^{34}$. O sujeito apreende o objecto num só 'golpe de vista', num ápice! Este carácter unitivo da intuição deve-se à simpatia e ao amor que existe entre todos os elementos do universo que, para os filósofos da escola romântica, Novalis e Schelling, representava o modo pelo qual a harmonia do cosmos está organizada. Esta simpatia não só possibilita o conhecimento das coisas, mas também estabelece uma relação, uma rede de 'inter-comunicações' entre todos os seres da natureza. O sujeito consegue, assim, unir-se a cada ser graças à sua capacidade intuitiva, que lhe proporciona um sentimento de ser 'um-com' o universo ${ }^{35}$.

33 Idem, "Nous trouverions également dans l'oeuvre de Georg Simmel des traces de cette esthétique vitaliste. Pour Simmel comme pour Bergson et Guyau, c'est d'un malentendu qu'est né le débat entre idéalisme et réalisme: les valeurs esthétiques sont à la fois objectives en ce que le sujet les a projetées très loin de sa conscience individuelle, et subjectives en ce que plus l'art manifeste une grande indépendance par rapport à l'individualité, plus il tend à la traduire d'une façon profonde et immédiate. L'art, comme par un coup de baguette magique, fait tomber les barrières qui s'interposaient entre le sujet et l'objet: en exprimant le vie immanente aux choses, il nous transporte d'emblée au sein de la réalité absolue en même temps qu'il nous fait toucher le tréfonds obscur de notre moi individuel. Cette esthétique, avec son caractère profondément immanentiste et vitaliste, ressemble encore à celle de Bergson.", "L'esthétique de Guyau et l'esthétique bergsonienne", Premières et dernières pages, p. 49.

34 Isabelle de Montmollin, La philosophie de Vladimir Jankélévitch, Paris, P.U.F., 2000, p. 109.

35 V. Jankélévitch, 'La 'sympathie' bergsonnienne n'est ni sentimentale ni intelectuelle, elle ne consiste pas non plus à s'extérioriser, à se projeter au-dehors, à ce partager en deux (un tel processus aboutirait à spatialiser, c'est-a-dire à tuer la conscience vivante), mais bien à se retrouver au coeur des choses et à saisir le plus dehors, l'absolue objectivité précisément à force de s'intérioriser et de vivre intensément son propre devenir psychique. N'est-ce pas ainsi, d'ailleurs, que des philosophes de la vie comme Schopenhauer et surtout Georg Simmel ont conçu la 
$\mathrm{Na}$ filosofia de Bergson, este tipo de pensamento intuitivo seria, então, um pensamento capaz de se colocar 'acima' do primado dos conceitos no Idealismo, formando um pensamento fluido capaz de acompanhar o movimento do real entre sujeito e objecto, absolutamente distinto do pensamento conceptual característico da inteligência. Segundo ele, a inteligência é uma faculdade destinada a operar sobre a matéria inerte, incapaz de trabalhar sobre o movente, porque o seu domínio próprio é o espaço. Pelo contrário, a intuição realiza um pensamento da mobilidade, uma filosofia do vivido que se vira para uma 'metafísica do concreto' e está muito mais ligada à temporalidade, à percepção dos momentos e dos instantes.

A arte e a experiência estética são um meio que, pela sua própria natureza, nos exige um pensamento intuitivo, e por isso mesmo, parece colocar-nos numa maior proximidade com o real. O sujeito que se deleita com a arte é aquele que, por um processo de simpatia, comunga com o ritmo, com a sintonia, e com o próprio fluir do estado de espírito da obra. Neste sentido, a experiência estética permite-nos transcender os limites conceptuais e os princípios lógicos da razão, sugerindo-nos aquilo que a linguagem habitual não consegue fazer-nos inteligir. De acordo com Bergson e Jankélévitch, a música seria a principal forma de arte por excelência, porque realiza um maior contacto intuitivo com a vida ${ }^{36}$.

A música, apresentando sempre uma natureza ambígua, repleta de atmosferas ambivalentes, vai permitir uma ligação profunda e imediata com a realidade, encerrando em si mesma vários graus de expressão inexpressiva, não sendo, deste modo, uma arte que exprime directamente, apenas alude e sugere ambientes. Jankélévitch, baseando-se nas filosofias de Bergson e Simmel, elege o Impressionismo como o 'estílo' artístico que mais se aproxima de uma vivência genuína do real, porque este movimento insurge-se contra a filosofia idealista do eu, centrado em si próprio, procurando a "impressão objectiva" do artista que está 'enamorado' ou numa relação de envolvência com a natureza e com a beleza evanescente da paisagem. Assim, a filosofia romântica do eu, que se apoiava no génio do artista, irá dar lugar progressivamente a uma filosofia do instan-

'sympathie' esthétique, qui n'est qu'une manière de ressaisir l'objectif en exprimant la vie subjective dans ce qu'elle a de plus profond et de plus intense? (...) La sympathie bergsoniemme n'a donc pas de point d'application sociologique: c'est la relation essentiellement intuitive et immanente à l'esprit individuel par laquelle la conscience, loin de s'éparpiller au-dehors, ne se retrouve dans les choses qu'en s'intériorisant davantage, c'est-à-dire en les vivant, en les absorvant dans le courant de son propre devenir, et non pas en se petrifiant dans leur immobilité à eux; à la limite, suivant Simmel comme suivant Bergson, objet et sujet ne font plus qu'un.", Premières et dernières pages, pp. 29-30.

36 Henri Bergson, La pensée et le mouvant. Essais et conférences, Ouevres, Paris, PUF, 1959, p. 1326. 
te, que procura as impressões do instante fugitivo, as belas paisagens, que captam o nosso olhar, e os 'momentos musicais' que arrebatam totalmente a alma... Em vez de encontrar as coisas no interior de si mesmo, o génio encontra-se consigo mesmo dilatando-se 'simpaticamente' para o mundo. O Impressionismo vai debruçar-se totalmente nas sensações e no inexpressivo, vira-se para as coisas, para a natureza, deixando as coisas falarem por si próprias, sem mediações, realizando uma espécie de 'super-realismo'. Tal realismo assemelha-se, de algum modo, à máxima da fenomenologia "ir às coisas mesmas", procurar o eidos da realidade através da vivência das coisas.

Encontraremos na questão da Stimmung, refere Jankélévitch, toda uma interpretação da noção de simpatia, que está presente não só na filosofia da paisagem de Simmel, mas essencialmente na filosofia musical em que está especialmente interessado. A noção de Stimmung terá um carácter bastante misterioso, sendo difícil atribuir-lhe um significado preciso dada a profundidade e a intensidade deste termo. Poderíamos associá-la, de um modo geral, a um "estado de alma"37, expressão de uma "atmosfera" ou de um "ambiente" invisível, impalpável, ou como Jankélévitch prefere, inefável.

No contexto da estética, Stimmung será o conceito essencial que permitirá fundamentar toda a filosofia da natureza e da paisagem, e será igualmente, como veremos, um conceito que sustenta as teses jankélévitchianas a respeito da música, na medida em que a expressão Stimmung significa, antes de mais, a 'consonância' musical entre os vários sons, uma espécie de harmonia, relembrando o antigo pitagorismo, onde todo o universo se deixava trespassar por uma música invisível e inaudível, a 'música das esferas', que ordenava o cosmos. Jankélévitch chega mesmo a utilizar a expressão "acústica interna", ${ }^{88}$ relacionando Simmel com Steffan George, de maneira a demonstrar que a 'sintonia' entre os diversos elementos não resulta de uma espécie de esquematismo interior, mas de uma 'ressonância' lírica que cria uma unidade formal.

Simmel, influenciado pelos precursores da Naturphilosophie, Christophe Oetinger, Schelling e Novalis, irá reconhecer a existência de uma ordem vital ou de um élan vital, se utilizarmos a expressão bergsoniana. Todavia, deveremos ter em atenção que esta 'filosofia da vida' romântica fazia coincidir em si as correntes que usualmente designamos de evolucionismo e de vitalismo, sendo que Simmel e Bergson enveredaram, posteriormente, pela vertente mais vitalista, na medida em que o evolucionismo tende a orientar a noção de vida para as ciências físico-químicas e

37 Georg Simmel, "Philosophie du paysage", La tragédie de la culture et autres essais, trad. Sabine Cornille e Philippe Ivernel, Paris, Rivages, D. L. 1993, p. 240.

38 V. Jankélévitch, “acoustique interne”, Préface, p. 48. 
para um certo biologismo. Ao invés, o vitalismo, sem renunciar à noção de 'evolução', concebe a vida como uma forma de 'pensamento vivo', uma evolução da consciência que não procura apenas perpetuar a espécie, mas pretende alcançar constantemente uma superação dos seus limites, uma 'ultrapassagem' das suas condições, mediante uma geração de formas imprevisíveis que estão presentes na natureza e na criação artística ${ }^{39}$.

A Stimmung será responsável por esta união simpática entre as diversas formas imprevisíveis da natureza e será o ponto de apoio da questão da paisagem, na medida em que só pode existir aquilo que designamos de 'paisagem' devido à existência de uma sintonia harmoniosa entre um conjunto de elementos, cuja união não é aleatória ou ocasional. Na verdade, todos os elementos parecem manifestar um acordo mútuo muito intrínseco, que nos deixa pressentir, de certo modo, um acordo teleológico profundo. A natureza não se assume, assim, como um mero conjunto de paisagens que se vão adicionando sucessivamente umas às outras, porque aparece-nos sempre como uma unidade indivisa, uma espécie de organismo, onde tudo trabalha harmoniosamente, apresentando uma função específica. Será, porém, importante estabelecer a destrinça entre 'natureza' e 'paisagem' que são aspectos distintos, embora estejam ambos na tangencia um do outro: a 'natureza' funciona como uma unidade e uma totalidade sem partes e sem qualquer fragmentação; e a 'paisagem' poder-se-ia considerar que é um 'olhar' que 'captou' um momento especial da natureza ${ }^{40}$. Imaginemos um pintor que com as suas pinceladas capta o azul do céu, as nuvens, um riacho rodeado por belíssimas árvores, etc... Imaginemos igualmente um fotógrafo que, com a sua objectiva, consegue captar ou 'agarrar' aquele pôr-do-sol inesquecível. Trata-se, como vemos, de pequenos momentos ou atmosferas que se tentam 'agarrar' através de um olhar quase mágico sobre a realidade. Por conseguinte, enquanto que a 'natureza' é tomada como uma totalidade indivisa, a 'paisagem' é algo individualizado e circunscrito àquele tempo e àquele lugar especificos.

A paisagem, de acordo com Simmel, será sempre um dos géneros preferidos do pintor ou do poeta, porque ao mesmo tempo que a natureza se exprime no que tem de mais profundo e mais objectivo, traduz-se na nossa alma por um grande número de reacções e "tensões" subjectivas, enriquece e intensifica o dinamismo imanente da nossa afectividade e a nossa actividade, encarna-se, por assim dizer, na nossa vida interna ${ }^{41}$.

39 Idem, Premières et dernières pages, pp. 17-19.

40 Op. Cit., Georg Simmel, "Philosophie du paysage", pp. 231-232.

41 V. Jankélévitch, "La paysage, suivant Simmel, sera toujours l'un des genres préférés du peintre ou du poète, parce qu'en même temps que la nature s'y exprime dans ce qu'elle a de plus profond et de plus objectif, elle se traduit dans notre âme 
Segundo Simmel, o papel do filósofo e do artista é 'simpatizar' com a natureza, criando-se, desta maneira, uma fusão entre o homem e o mun$\mathrm{do}^{42}$. O estado de espírito de sujeito, que é subjectivo, coincide com determinados lugares e paisagens, tornando-se objectivo, ou seja, objectivizando-se nelas. Sendo assim, dá-se uma união entre o interior e o exterior, na medida em que a subjectividade e a afectividade humana é que reconhecerão e darão um significado à paisagem contemplada. Simmel faz referência ao amor e ao sentimento poético para exemplificar a envolvência que se gera em torno de tal experiência estética ${ }^{43}$. De algum modo, o pensamento simmeliano relembra bastante o lirismo presente no Idealismo mágico de Novalis, que interliga a matéria e o espírito, demonstrando-nos que a imaginação criadora deve libertar o homem da ilusão que o leva a separar a natureza do espírito, pois o pensamento e a matéria estão envolvidos um no outro - afirmando que o mundo é sonho e o sonho é mundo.

Vladimir Jankélévitch aprecia fundamentalmente o facto de Simmel acentuar o carácter singular da paisagem - 'aquela paisagem e nenhuma outra' - no sentido em que é insubstituível e não se pode confundir ou trocar por outra experiência. Além da sua singularidade, verifica-se também a sua incomunicabilidade, visto que a apreensão daquilo que é considerado como paisagem vai ser uma experiência de um sujeito individual. Não se trata, desta forma, de uma experiência colectiva, porque cada olho vê e vivencia de uma forma única e intransmissível. Na filosofia jankélévitchiana, esta constatação vai estar presente em toda a questão da nostalgia, conceito fundamental na sua obra, e na experiência estética musical. A nostalgia é um reconhecimento da passagem do tempo que se caracteriza pela saudade, pela recordação e, de certo modo, por um reviver o passado, relembrando os doces ou dramáticos momentos vividos. No fundo, o homem possui em si esta capacidade nostálgica graças à

par un nombre très grand de réactions et de «tensions» subjectives, elle enrichit et intensifie le dynamisme immanent de notre affectivité et de notre activité, elle s'incarne pour ainsi dire dans notre vie intérieure.", "III. L'esthétique de Guyau et l'esthétique bergsonienne", Premières et dernières pages, p. 49.

42 Paulo Frazão Roberto: "Por isso, quando Simmel formula a tese segundo a qual "a arte vem da vida" quer certamente com isso significar que existe um principio geral de intensificação de vida cujas energias, qual élan vital (Bergson), 'inundam' esse local (no seu enquadramento aberto na diferença 'onto-orgânica' em relação ao ser e à potência global de vida da natureza) nesse momento em que o homem nele se encontra envolvido presencialmente, dando assim origem, nessa 'ambiência vital' (Stimmung), a um 'estado de ânimo' (Stimmung) em que essa paisagem é sentida e vivida, com-junta e simultaneamente ('o simples vivido como uno e indiviso'), como uma unidade estética.", "A harmoniosa pregnância vital da paisagem natural em Georg Simmel”, Philosophica n. ${ }^{\circ} 29$, p. 82.

43 Op. Cit., Georg Simmel, "Philosophie du paysage", p. 243. 
Stimmung que lhe permite recordar de uma determinada maneira, tão especial, certos momentos inesquecíveis: a lembrança da nossa cidade natal, do nosso país, das pessoas que se cruzaram pelo nosso caminho. Geralmente, estas recordações são acompanhada por um sentimento de perda e de tristeza, porque o passado já não pode retornar e caminha para o nada, para o vazio e para a morte... Recordar surge, assim, como uma forma de perpetuar a vida, tornar presente o passado, numa tentativa de 'prendermos' e ou nos 'apoderarmos' daquilo que é evanescente e que incessantemente nos escapa. Esta irreversibilidade do tempo, geradora de tristeza e melancolia, vai ser a principal característica da arte musical, pois a música é tempo, vive do tempo e consome-se no tempo. Toda a experiência musical é da ordem do efémero, manifesta um charme e um poder de encantamento no homem que Jankélévitch compara a um perfume que nos deixa inebriados. Na verdade, a Stimmung poderia ser apresentada como aquilo que prende o homem à vida, o sopro vital e anímico que habita o interior do homem, a sua alma, que dá sentido e reconhece a beleza em todas as coisas. A Stimmung seria, em suma, a força psicológica, anímica ou, poderíamos dizer, espiritual, que cria toda a experiência amorosa entre o homem e o seu mundo, que na teologia russa se designa de sobornost, a comunidade simpática entre todos os seres, uma espécie de sinfonia universal.

A presença do pensamento de Georg Simmel na filosofia jankélévitchiana parece surgir de um modo muito discreto e, por vezes, dir-se-ia que é quase inapreensível. Poderíamos ler toda a obra de Jankélévitch sem necessitar sequer de conhecer os escritos deste grande autor alemão, embora não pudéssemos afirmar o mesmo a respeito de Platão, Aristóteles ou Bergson. Existem efectivamente certos autores fundamentais que, sem possuirmos um conhecimento aprofundado, nunca poderíamos compreender a filosofia de Jankélévitch. No caso de Simmel, a sua influência aparece-nos, inicialmente, de um modo muito suave, porém, se nos detivermos a estudar empenhadamente este autor, iremos descobrir inúmeras relações extremamente essenciais que nos darão uma visão mais detalhada dos motivos que levaram Jankélévitch a seguir uma determinada linha de pensamento. Deveremos, por isso, acrescentar que Simmel manifesta-se em todas as 'entrelinhas' da filosofia jankélévitchiana e a sua presença é mais importante do que à primeira vista nos possa parecer.

A influência da "filosofia da vida" vai ser muito importante na concepção estética de Jankélévitch e isso deve-se, provavelmente, ao facto de certas questões levantadas por Simmel estarem bem patentes na filosofia russa contemporânea. A Lebens- e Weltanschauung e todo o pensamento 
filosófico do final do século XIX tiveram relevância no pensamento ortodoxo russo. A primeira metade do século XIX foi marcada pela "hegemonia do idealismo alemão" na Europa, que esteve vigente nas escolas russas durante muito tempo, pois existiam muitos seguidores de Kant e Hegel $^{44}$. Apesar de Jankélévitch viver em França, acompanhou a tradição russa muito de perto e vai aderir às correntes místicas, um pouco 'marginais' ou menos seguidas pelo academismo russo. A revivescência da filosofia grega, do neoplatonismo, e do idealismo de Schelling será valorizada pela ortodoxia russa. Criando-se, deste modo, uma certa oposição entre o ocidente e o oriente, onde a filosofia ocidental é encarada sobretudo como um pensamento racional e abstracto, subordinado à solidez dos conceitos, enquanto que a filosofia tipicamente russa vai salientar um certo vitalismo, imanentismo e espiritualismo ${ }^{45}$. Compreende-se, tendo em conta estes antecedentes, o especial interesse de Jankélévitch por Simmel e por tudo aquilo que ele representa na realização da "filosofia da vida".

Jankélévitch vai acentuar essencialmente o 'carácter de ruptura' de Simmel relativamente ao Idealismo kantiano e creio que, por vezes, se esquece de demonstrar o 'carácter de continuidade'. Simmel costuma ser, geralmente, apresentado enquanto neo-kantista, na medida em que não negou a doutrina de Kant, orientou-a de um modo inovador e ligou-a com uma "filosofia da vida". Todavia, Jankélévitch insiste mais na ruptura e pretende sobretudo refutar Kant devido à sua aversão, bastante explícita, contra o formalismo e contra a noção de 'conceito'. A expressão 'conceito', na filosofia jankélévitchiana, será algo totalmente insuportável, visto que se opõe contra a ideia de 'fluxo vital' indomável e imprevisível. Neste sentido, Jankélévitch aprecia Simmel pelo seu aspecto inovador no que diz respeito à filosofia alemã precedente e, como não poderia deixar de ser, fica entusiasticamente arrebatado pela noção de Stimmung, porque lhe permite abrir caminho para uma estética da música, assente na constatação do inefável, da nostalgia e do amor.

A Stimmung simmeliana surge como uma ideia única na história da estética, e ao lermos os escritos de Jankélévitch compreenderemos como esta ideia prodigiosa, deu alento e serviu mesmo de 'ponto de apoio' para sua filosofia de recorte impressionista e vitalista. Toda "a arte vem necessariamente da vida" e quando o homem caminha alienado da questão da vida, percorre um percurso contra si próprio, contra a constatação do fenómeno existente. A doutrina de Jankélévitch não desenvolve o pólo racional, aliado a raciocínios ou deduções lógicas, nem se rege por prin-

44 V. Jankélévitch, "7. Les thèmes mystiques dans la pensée russe contemporaine", Premières et dernières pages, p. 101.

45 Ibidem, p. 109. 
cípios lógicos. Vive, ao invés, numa atmosfera ambígua, algumas vezes, vaga, porque, segundo o autor, aquilo que há de mais profundo na vida é o seu carácter indefinível que fere o orgulho filosófico racional, porque escapa à nossa compreensão. No fundo, Jankélévitch ama sentir esse sentimento do sublime, esse carácter de êxtase que se dá na contemplação estética e que deixa o homem boquiaberto e sem palavras.

\title{
RESUMO
}

O presente trabalho tem como principal finalidade investigar a relação entre a filosofia de Vladimir Jankélévitch e as obras de Georg Simmel. Semelhante tarefa leva-nos a enveredar por três capítulos essenciais: O primeiro capítulo diz respeito ao início da "filosofia da vida", explanando a importância da "vida", "experiência" e "intuição" enquanto conceitos que emergem com um novo significado na filosofia. $\mathrm{O}$ segundo capítulo, dedicado às relações entre arte e vida, baseia-se na teoria da Lebensanschauung de Simmel. E, no terceiro capítulo deste artigo, tentamos expor a "filosofia da paisagem" e a ideia de Stimmmung que atravessa não só o conceito de paisagem mas também o conceito de música tal como nos é apresentado na estética musical de Jankélévitch.

\begin{abstract}
First of all, the main subject of the present work is to investigate the relation between Vladimir Jankélévitch's philosophy and Georg Simmel's works. Such task accomplishes three streams: The first chapter is concerned with the beginning of "philosophy of life", explaining the importance of "life", "experience" and "intuition" as new concepts that arise with a new meaning in philosophy. The second chapter, devoted to the relations between art and life, is based in Simmel's Lebensanschauung theory. And in the third chapter of this work, we attempt to expose the "philosophy of landscape" and the idea of Stimmung that surpasses not only the concept of landscape but also the concept of music in Jankélévitch's musical aesthetics.
\end{abstract}

